\title{
Finite Element Analysis of Honeycomb Sandwich Composite Structures With Various Joints
}

\author{
R.Karthikeyan ${ }^{1}$, P.S.Mohanasaravanan ${ }^{2}$, N.Kalaimani ${ }^{3}$ \\ 1,2,3 Assistant Professor, Department of Aeronautical Engineering, Bharath Institute of Higher Education and \\ Research, Chennai.
}

Article History: Received: 11 January 2021; Accepted: 27 February 2021; Published online: 5 April 2021

\begin{abstract}
This work focuses on the numerical investigation of mechanical properties of aluminium honeycomb sandwich composite structures with lap and butt joints. The joints are bonded using adhesive, welded and bolted which were designed using CATIA software. The static and dynamic structural analyses were performed to compute the mechanical properties of aluminium honeycomb composite structures with various joints using ANSYS software. Finally, the models were developed for estimating the failure strength of joints in honeycomb sandwich composite structures.
\end{abstract}

KEYWORDS: Sandwich panel; Composite structure; Joints; Numerical model; Mechanical strength.

\section{Introduction:}

In recent years, the usage of sandwich composite structures is continuously increasing due to their excellent compressive and out-of-plane shear properties [1]. Also, the sandwich composite structures are widely used in various manufacturing sectors such as marine, building, aerospace, automobile industries etc [2]. The typical sandwich composite structures consist of top and bottom face sheet which covered the central core materials. Generally, the central core material is made in the shape of truss, honeycomb and foam in sandwich composites. Materials such as Nomex, Aluminium and Polypropylene are regularly used as core in sandwich composites. The face sheet materials are carbon fiber reinforced plastics (CFRP), glass fiber reinforced plastics (GFRP) and aluminium are commonly used for fabricating sandwich composite structures.

However, the sandwich composite panels are used as various structural components ships, beams, cars and so forth. Further, the structures are not only difficult to fabricate and also very expensive in computational analysis to develop the models [3-5]. This is due to large and complex shapes of honeycomb core are used to construct the panels $[6,7]$. In order to eliminate these limitations, the complex shape of core materials are replaced by a same volume of simple shape without changing the orthotropic properties of the composite panels can be manufactured [8-11].

The present work developed the methodology for analysis of honeycomb sandwich composites structures using homogenization technique. It is based on the strain energy criterion to develop the model for analysis the mechanical properties. Additionally, the sandwich structures consist of face sheet and hexagonal core were used for manufacturing composite panels. Also the model was developed for predicting the failure strength of different joints in sandwich composite panels $[6,8]$. Moreover, the simple equivalent volume of core was used for finite element analysis. A single equivalent representative cell was considered for analysis to compute the effective elastic orthotropic properties [9]. Hence, the single element which repeats itself on the direction of in-plane and the elastic properties were obtained based on the single cell with equivalent volume [10]. The similar methodology was used for the analysis of sandwich beam. Four-point and three-point tests were simulated using 2D finite element analysis. Finally, the experimental and simulation results were validated for the failure strength in various joints of sandwich composite structures.

\section{Modelling of sandwich panel}

The composite sandwich panel is modelled by using CATIA software, the top and bottom panels are fully closed and inside the sandwich panel honeycomb structure is fixed the adhesive joints layer is modelled inbetween the panels, for welded joints, welding part is modelled in top and bottom and for bolded joints are shown in Figs.1 and 2. The maximum deformation, stress, strain and impact strength of the aluminium honeycomb composite structures are shown in Figs. 3 to 14.

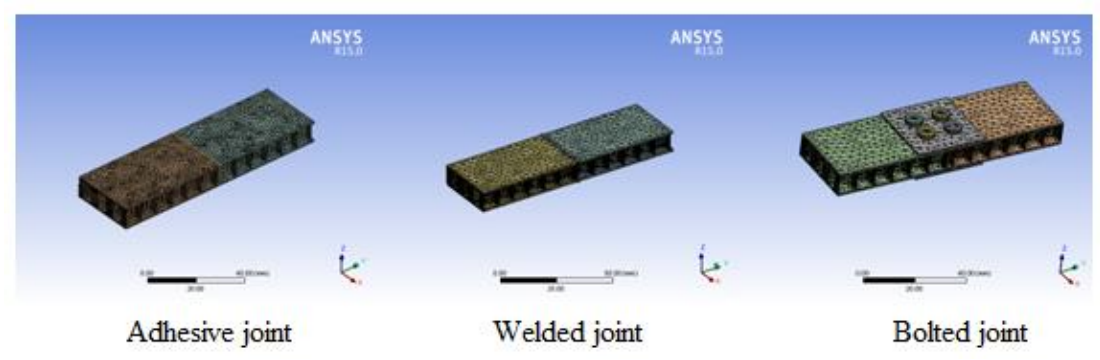

Fig.1: Different type of designed butt joints 


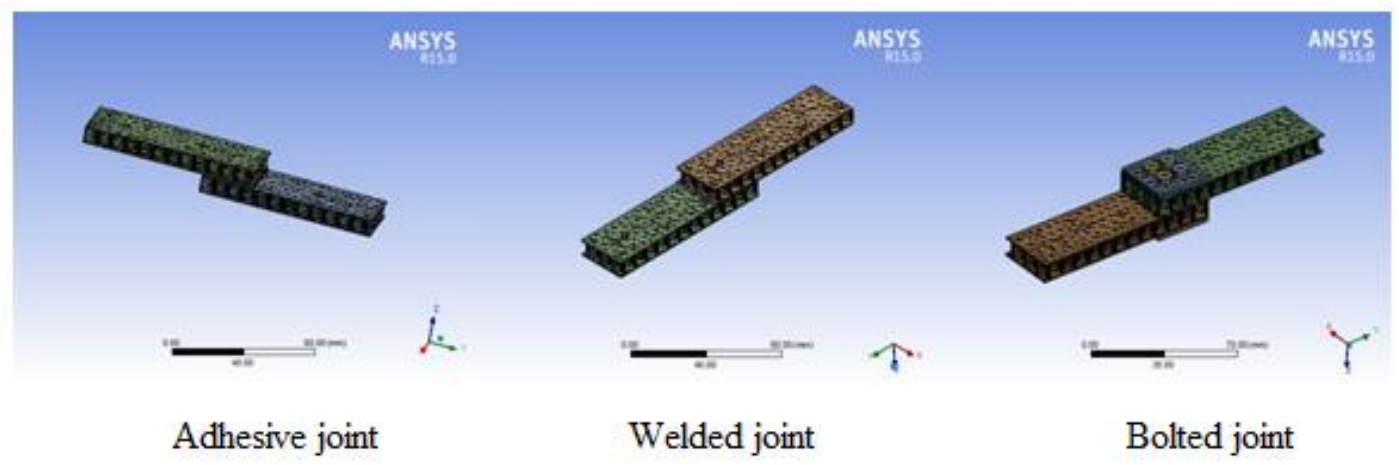

Fig.2: Different type of designed lap joints

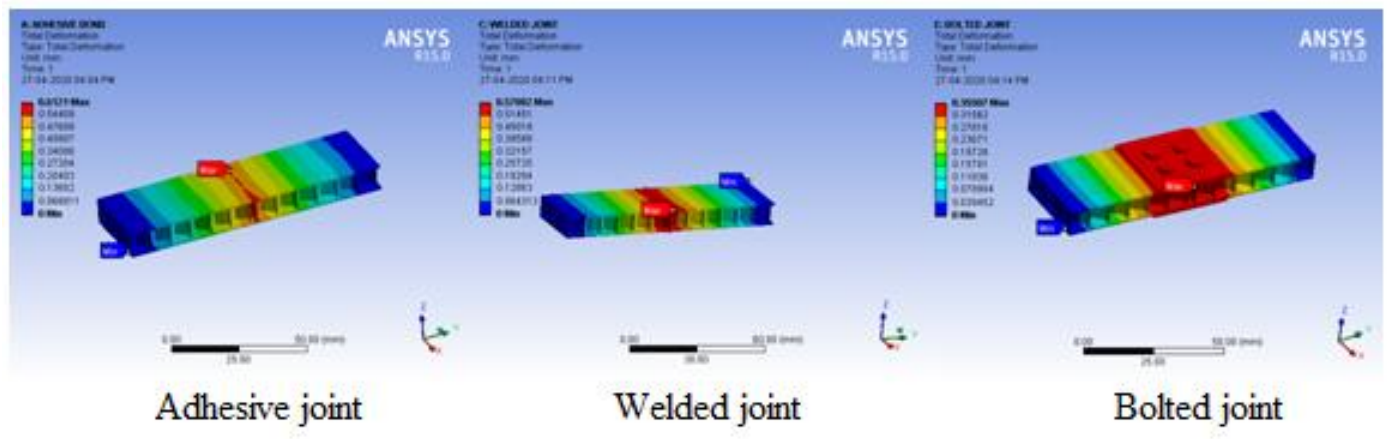

Fig.3: Analysis of deformation in different butt joints

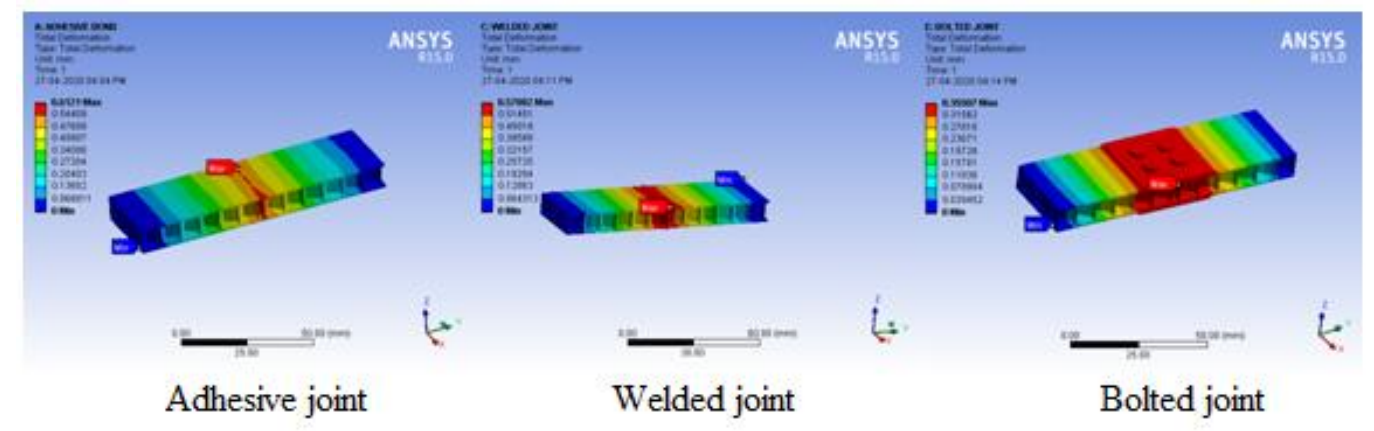

Fig.4: Analysis of deformation in different lap joints

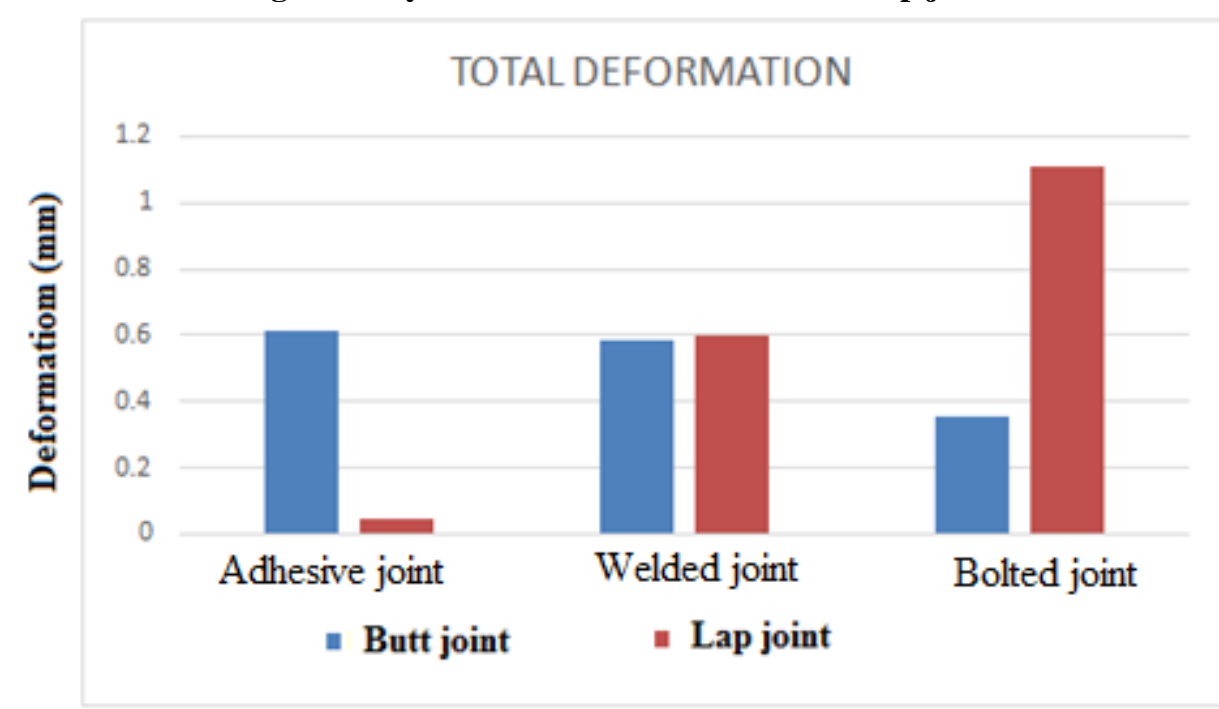

Fig.5: Comparison of deformation in various joints of aluminum honeycomb composite panels 


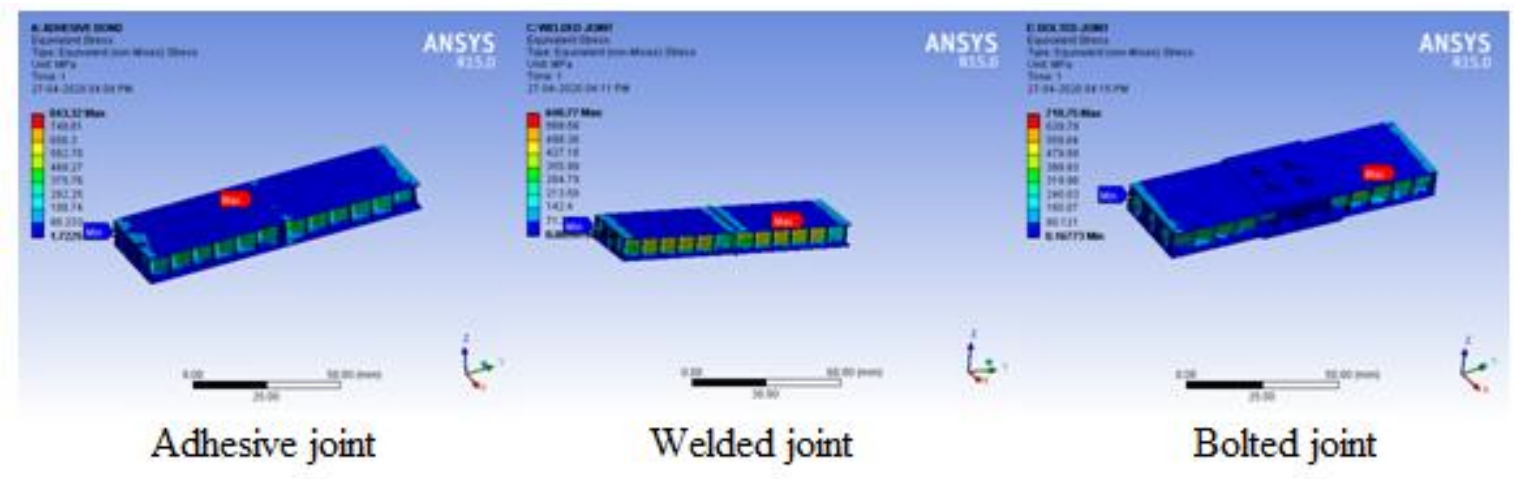

Fig.6: Stress analysis of different butt joints

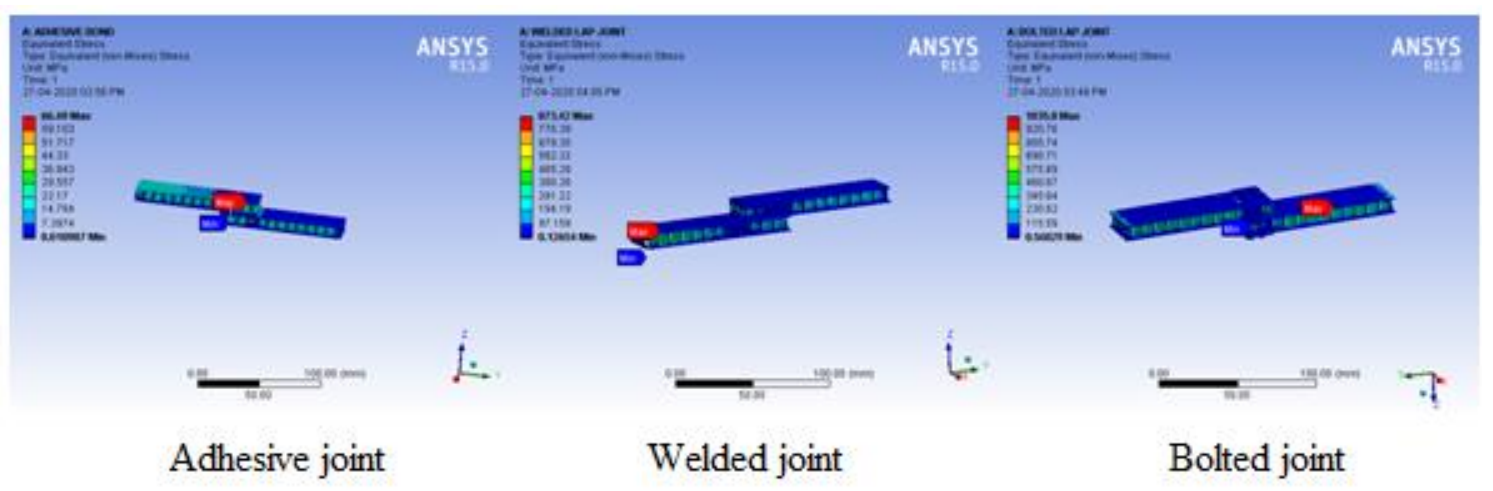

Fig.7: Stress analysis of different lap joints

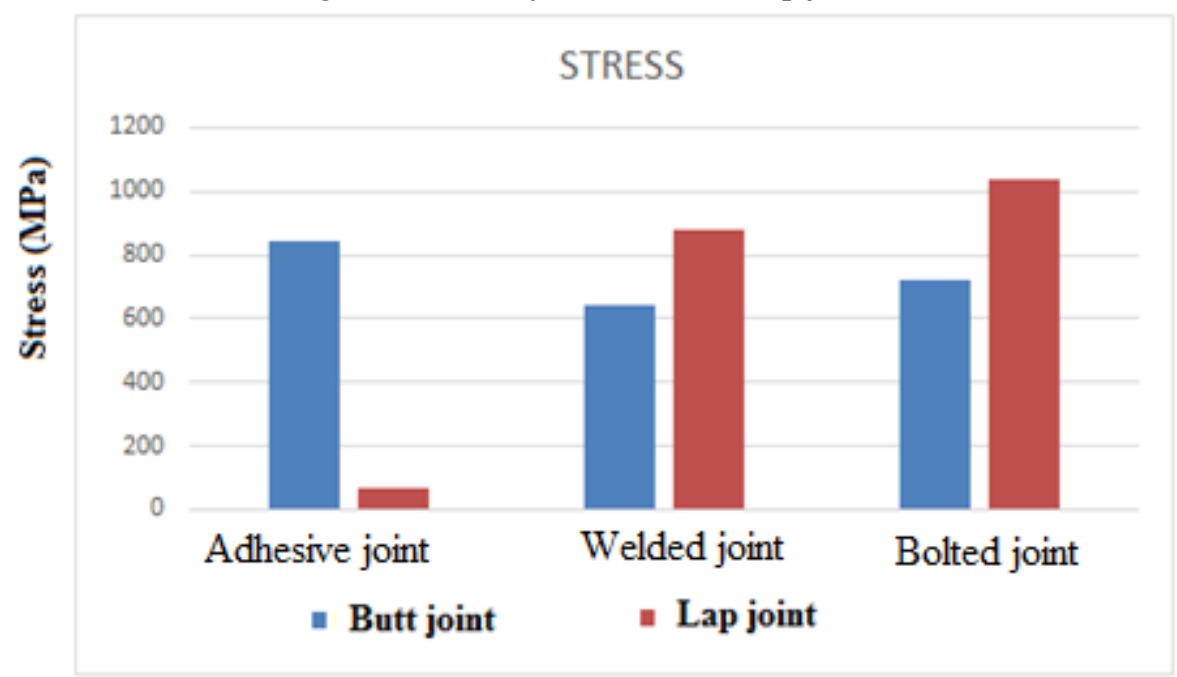

Fig.8: Comparison of stress in various joints of aluminum honeycomb composite panels

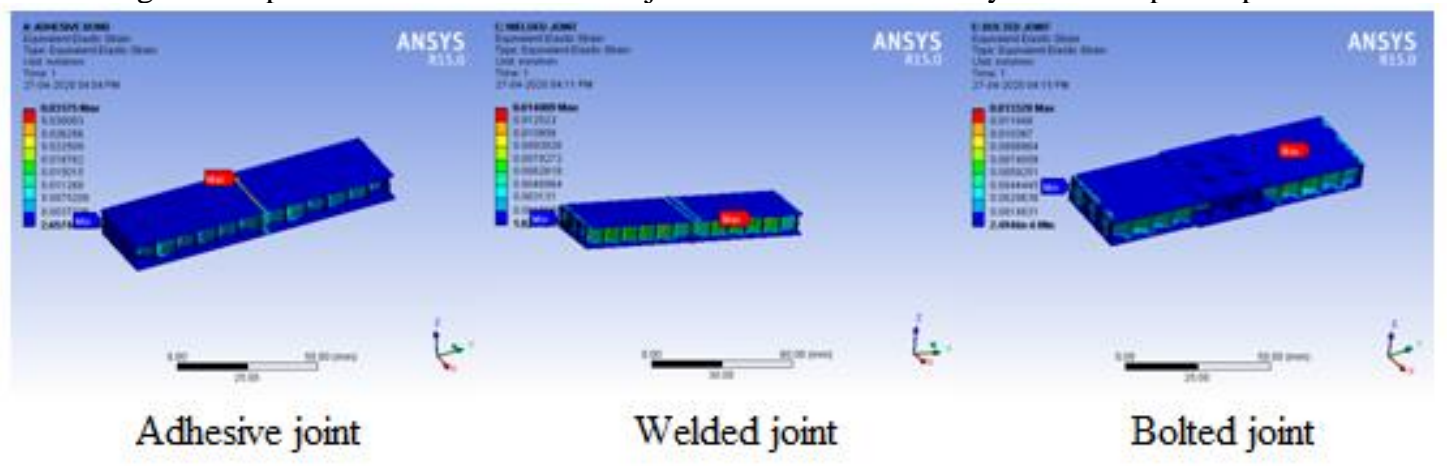

Fig.9: Strain analysis of different butt joints 


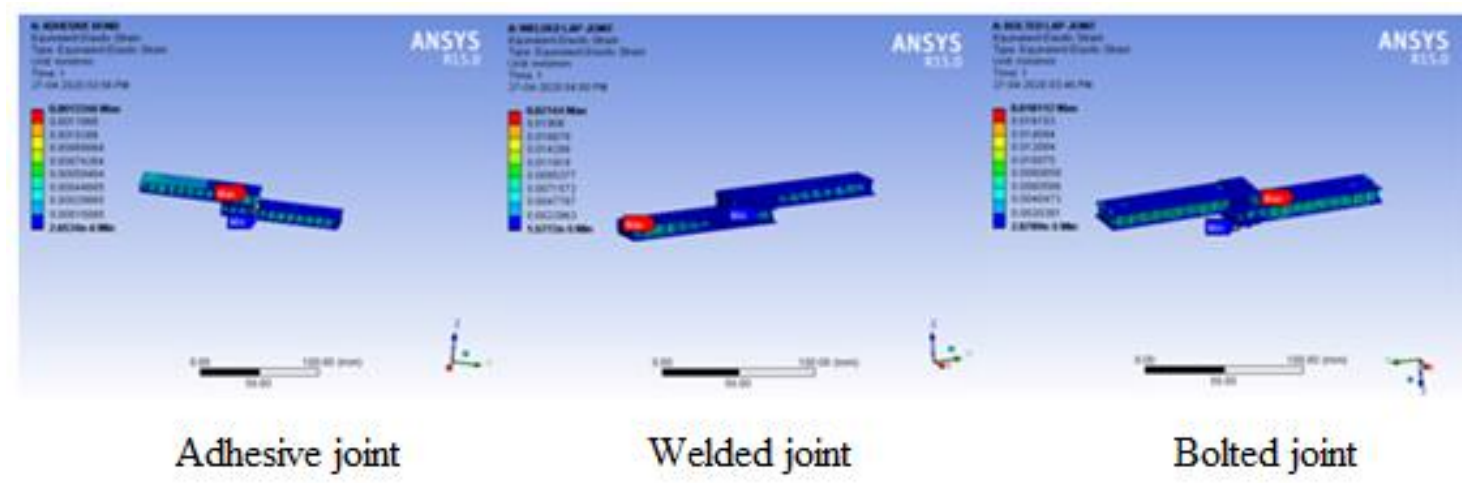

Fig.7: Strain analysis of different lap joints

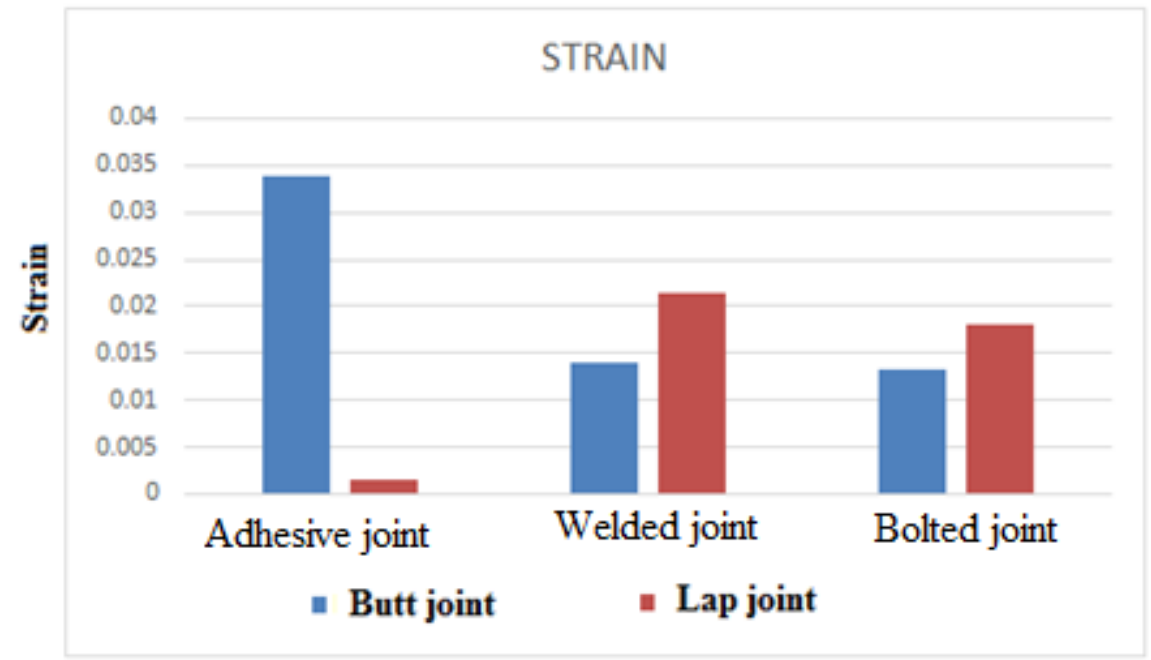

Fig.11: Comparison of strain in various joints of aluminum honeycomb composite panels

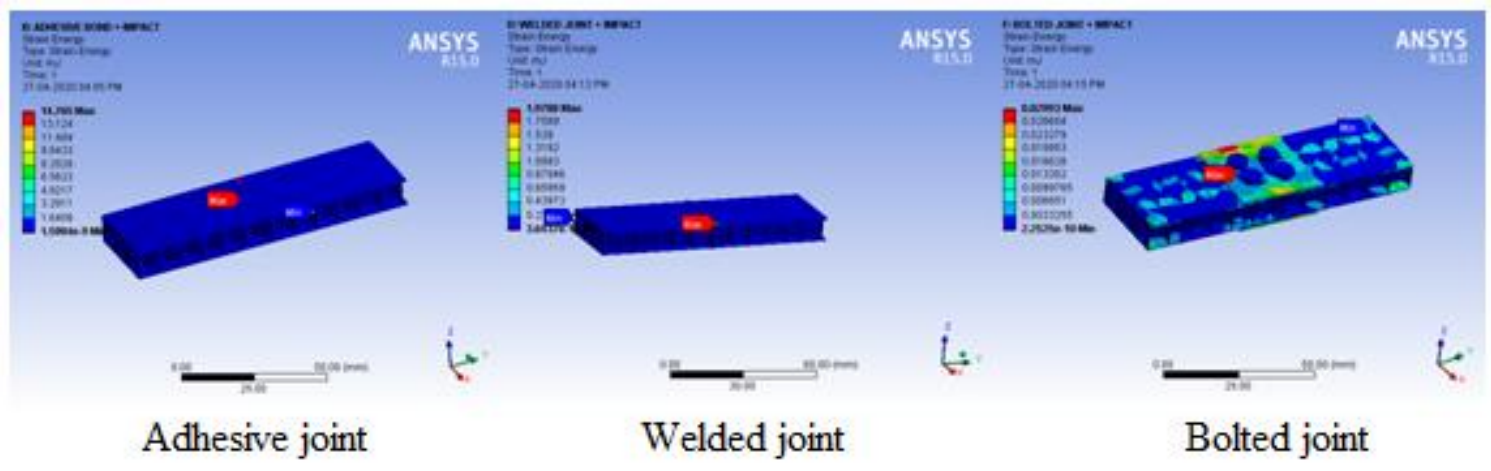

Fig.12: Impact analysis of different butt joints

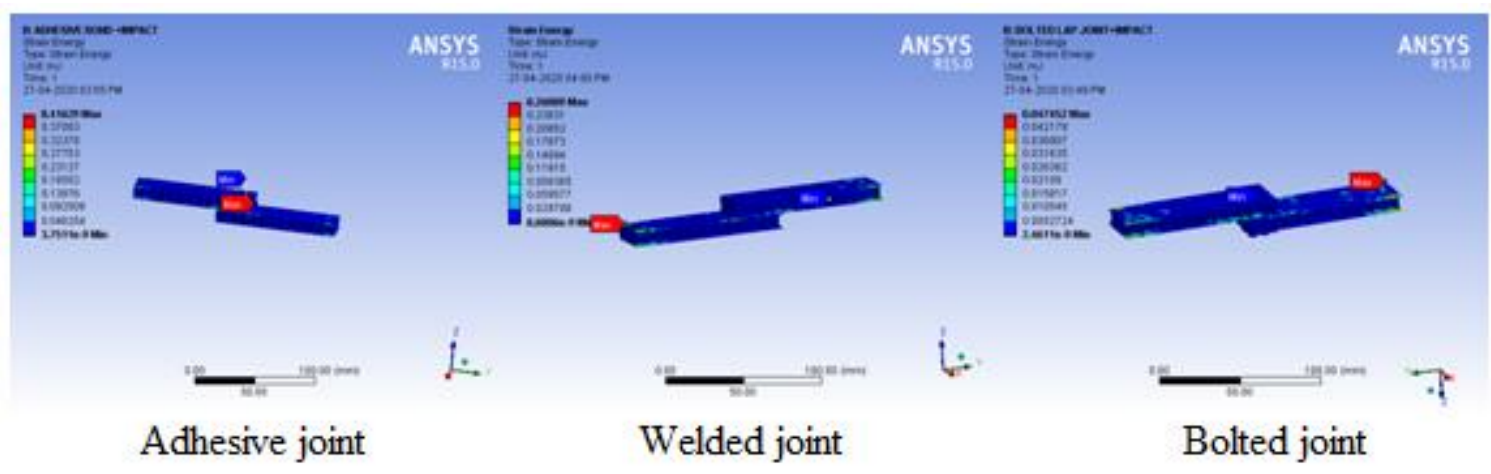

Fig.13: Impact analysis of different lap joints 


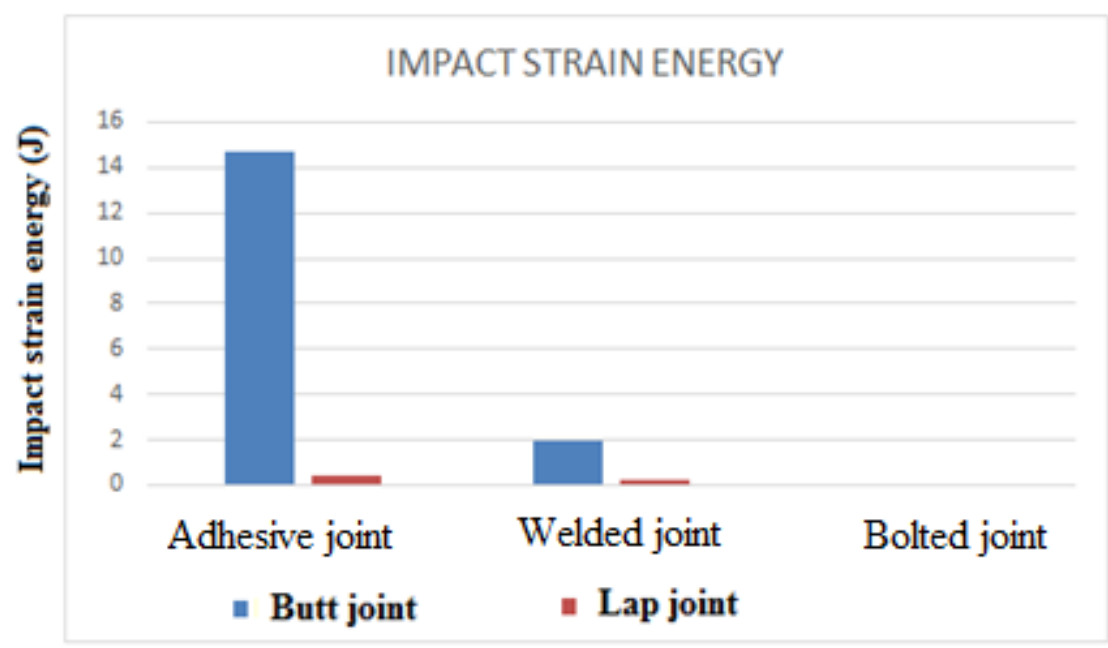

Fig.14: Comparison of impact energy absorption in various joints of aluminum honeycomb sandwich composite

\section{Conclusion}

panels

The structural analysis of the sandwich panel composite material with various joints of lap joint and butt joints was performed using ANSYS workbench software. Aluminium honeycomb sandwich composite panels are fixed with different joints like adhesive, bolted and welded are subjected to static and dynamic load. The results such as total deformation, stress, strain and impact strain energy are compared for all joints. Higher impact strength and lower impact energy absorption was observed for bonded and bolted joints. Finally, this study concluded that the bonded and bolted joints can be used for making the joints in sandwich composite panels.

\section{References}

1. W. Burton, A. Noor. Assessment of continuum models for sandwich panel honeycomb cores. Computer Methods in Applied Mechanics and Engineering (1997), 145(3-4): 341-360.

2. L. Gibson, M. Ashby. Cellular solids: Structure and properties, Pergamon, Oxford, U.K. (1988).

3. S. Kelsey, R. Gellatly, B. Clark. The shear modulus of foil honeycomb cores: A theoretical and experimental investigation on cores used in sandwich construction. Aircraft Engineering and Aerospace Technology (1958), 30: 294-302.

4. F. Meraghni, F. Desrumaux, M. Benzeggagh. Mechanical behavior of cellular core for structural sandwich panels. Composites Part A: Applied Science and Manufacturing (1999), 30: 767-779.

5. J. Penzien, and T. Diriksson, Effective shear modulus of honeycomb cellular structure. AIAA J., 2 (1964) 531-535.

6. J. Zhang, M. Ashby. The out-of-plane properties of honeycombs. International Journal of Mechanical Sciences (1992), 34:475-489.

7. Remmelt Andrew Staal. Failure of sandwich honeycomb panels in bending. PhD thesis (2006).

8. Shadi Omar Mohammad Balawi. Effective mechanical behavior of honeycombs: theoretical and experimental studies. Ph.D thesis (2007).

9. I. G. Masters, K. E. Evans. Models for the elastic deformation of honeycombs. Composite structures (1996), 35: 403-422.

10. Dai-Heng Chen, Hirokazu Horii and Shingo Ozaki. Analysis of in-plane elastic modulus for ahexagonal honeycomb core: analysis of young's modulus and shear modulus. Journal of Computational Science and Technology (2009), 3(1): 1-12.

11. L. Chun, M. Zhao, L. Jie, J. Wang, Y. Gao, X. Cui, P. Chen. Stress Distribution on Composite Honeycomb Sandwich Structure Suffered from Bending Load. Procedia Engineering (2015), 99: 405-412. 